December 2017

\title{
Bowraville and Phoebe's Fall: award-winning Australian podcasts from the media formerly known as print
}

Wendy Carlisle

formerly Australian Broadcasting Corporation

Follow this and additional works at: http://ro.uow.edu.au/rdr

Part of the Audio Arts and Acoustics Commons, Australian Studies Commons, Digital Humanities Commons, Indigenous Studies Commons, and the Radio Commons

Recommended Citation

Carlisle, Wendy, Bowraville and Phoebe's Fall: award-winning Australian podcasts from the media formerly known as print, RadioDoc Review, 3(2), 2017.

Research Online is the open access institutional repository for the University of Wollongong. For further information contact the UOW Library: research-pubs@uow.edu.au 


\title{
Bowraville and Phoebe's Fall: award-winning Australian podcasts from the media formerly known as print
}

\begin{abstract}
Digital technology has democratised the audio storytelling space in a quite profound way. This article compares two major podcast investigations produced by established Australian newspaper mastheads: Bowraville by The Australian, and Phoebe's Fall by The Age. Bowraville examines the unsolved murders of three Aboriginal children in the 1990s - all of whom came from the same small town. Phoebe's Fall investigates the bizarre death in a garbage chute of a luxury Melbourne apartment building of 24-year-old Phoebe Handsjuk and her troubled relationship with her much older boyfriend.

In depicting what have been described as the three essential ingredients of a successful podcast - story, character, voice - these podcasts employ different approaches. Bowraville was structured chronologically, hosted by Dan Box cast as the sleuthing journo in true crime style. As co-hosts of Phoebe's Fall, Richard Baker and Michael Bachelard deployed conversational banter, with episodes arranged thematically. Importantly, Bowraville had superior access to the main players in the drama and was strongly tethered against place. In contrast Phoebe's Fall had limited access to the players and was tightly constrained by defamation laws.

For the audio journalist, the interview is partly a performance piece. Audio story telling exists as a series of dramatic events unfolding through compelling characters against a story arc. It has to have the appearance of sweeping simplicity. It needs scene-setting, relevant facts. It has to break across the listener like a good wave.

Partly as a result of Bowraville, legal changes are afoot. Phoebe's Fall left its mark, too. Public pressure has prompted a review of the Victorian Coroner's Act, examining whether there ought to be more ways of revisiting a coronial finding. There's never been a better time for long form audio investigative journalism.
\end{abstract}

\section{Keywords}

podcasting, audio storytelling, true crime, investigative journalism 


\section{Bowraville and Phoebe's Fall: award-winning Australian podcasts from the media formerly known as print.}

Bowraville podcast, 6 episodes, by Dan Box and Eric George for The Australian newspaper,

May 2016

https://www.theaustralian.com.au/in-depth/bowraville

https://player.whooshkaa.com/shows/bowraville

Phoebe's Fall podcast, 6 episodes, by Michael Bachelard, Richard Baker, Siobhan McHugh, Tom McKendrick, Julie Posetti, Tim Young for Fairfax Media, Sept-October 2016 https://www.theage.com.au/interactive/2016/phoebesfall/related.html

\section{Reviewed by Wendy Carlisle}

There are two podcasts series from last year that are must-listens for those interested in investigative long form storytelling.

Both came from the media formerly known as print. The Australian produced Bowraville, which picked up a Walkley award for best documentary or podcast in 2016, and Fairfax Media gave us Phoebe's Fall, which also won a prestigious audio journalism prize, the Quill, also in 2016. It would later win two other national awards and the gold award at the New York Radio Festival.

It's worth letting that sink in for a minute. Former print mastheads took out the prestigious long form audio journalism awards last year. Nobody saw that coming.

"We didn't quite know what we were getting into," Dan Box from The Australian told $\mathrm{me}^{1}$, while Fairfax's Richard Baker summed it up this way: "podcasting wasn't really on The Age's agenda".

Each podcast series chose different narrative styles. Crime reporter Dan Box immediately cast himself as the sleuthing journo in true crime style. Richard Baker and Michael Bachelard shared the mic in Phoebe's Fall, deploying conversational banter to progress the story, which was intended to focus more on the journalistic project and the difficulties in telling the story than on telling the story itself.

Bowraville examines the unsolved murders of three Aboriginal children in the 1990s - all of whom came from the same small town in New South Wales. Phoebe's Fall investigates the bizarre death in a garbage chute of a luxury Melbourne apartment building of 24-yearold Phoebe Handsjuk and her troubled relationship with her much older boyfriend, Antony Hampel.

\footnotetext{
${ }^{1}$ Email to the author 14 January, 2017
} 
Bowraville was structured chronologically, while Phoebe's Fall was arranged thematically around topics the reporters wanted to analyse and discuss. Importantly, Bowraville had superior access to the main players in the drama and was strongly tethered against place. In contrast Phoebe's Fall had limited access to the players and was obviously tightly constrained by defamation laws.

In this review I'm comparing these different approaches and examining how well their stories were told.

\section{Essential ingredients}

Noted US podcasting industry figure Eric Nuzum, former Vice-President of NPR and now head of content at Audible.com, recently summed up the three things that make up a good podcast: ${ }^{2}$

\section{Story}

Character

Voice

'Story' refers to what story you are going to tell?

The characters are the 'talent' or as I like to think of them, the real people and players. The closer they are to the action the better. Even better is capturing on tape the real time action and the drama. That's where the gold is and it requires great skill to capture it. Finally, 'voice' is the narrator who must be the story teller. They must provide context and pace. But more than anything they must have something to say.

Indeed the very first thing any editor will ask is: what is your story and how are you going to tell it?

It's a trick question.

And it's a trick because audio story telling exists as a series of dramatic events unfolding through compelling characters against a story arc. It has to have the appearance of sweeping simplicity.

Much like telling a good story around the campfire, it has to unfold with one sequence leading to another. It needs scene-setting, relevant facts. It has to break across the listener like a good wave.

"The scene is never an end in itself, in a story the ultimate point is action. The wants and needs of the characters drive the plot forward through a series of scenes, each making overall points to the story's essential message," wrote Jack Hart in Storycraft. ${ }^{3}$ As the eminent media scholar Marshall McLuhan said, "the medium is the message" and the message of this is that the medium will determine the best platform for your story.

\footnotetext{
${ }^{2}$ Speaking at Audiocraft conference, University of Technology, Sydney, 10 June 2017.

${ }^{3}$ Hart, J, 2011. Storycraft: the complete guide to writing narrative non-fiction. University of Chicago Press: Chicago. p.90.
} 
Brian Reed, who made the seminal long form podcast $S$ - Town, applies this criterion closely. Talking to Marc Fennell on $A B C \mathrm{RN}^{4}$, he said he knew immediately that his protagonist, John B. McLemore, was great talent with a story to be told. Reed didn't make a story about S-Town because it was an "important story" (although it was) but because it satisfied other more crucial criteria. Reed said the story had to "be engaging and engrossing" and it had to "be told by the people in it".

John B. McLemore was one of those "people" and what Reed grasped was that S-Town could not be told if not for John B. McLemore.

Phoebe's Fall confronted an enormous hurdle in telling its story. Significant key players declined to speak (the police, Anthony Hampel, his family, Counsel assisting the coroner and the coroner himself), as Richard Baker noted:

"We had to deal with a Coroner who refused to use his discretion to release audio from Phoebe's inquest. This meant we had to rely on actors to read transcripts. We also faced ongoing suppression orders over the entire police brief of evidence to the inquest, even though a finding had been handed down two years ago." 5

Which boiled down to this. Instead of being told entirely "by the people in it", the makers also had to rely on re-enactments and readings and a decision was taken to overcome these gaps by having two reporters discuss them. The reporters thus were talking about what happened in a second or third-hand way rather than letting the characters tell their first-hand stories.

In contrast, Bowraville had a rich cast of witnesses and players: the families, townspeople, police officers, the prime suspect himself and most of all a number of real time action sequences which pulled the tension as tight as catgut. Coupled with recordings on location which created a sense of place, this was a series rich in texture, mood and movement.

\section{The power of an opening}

The opening sequences of any story, as Eric Nuzum told the 2017 Audiocraft Conference, "(is) meant to get you in a very deliberate space."

It's meant to get you hooked.

In Bowraville the tease opened thus:

SFX music. haunting piano

MAN 1:We're talking about a serial killer, New South Wales police don't have much experience investigating serial killings.

\footnotetext{
${ }^{4}$ Download This Show, ABC RN, 26 May 2017.

${ }^{5}$ Walkley Magazine, December 2016
} 
WOMAN 1: I can't picture him being a murderer, you know. I can't picture him doing that to those kids really.

WOMAN 2: I want him to go to gaol. Want justice:

and I still wait for justice

WOMAN 3: justice..

MAN 2: ...justice ...

WOMAN :..justice..

WOMAN: ... all we want is justice

WOMAN: ...get us into court

MAN: and this is unique as far as I know, this hasn't happened in NSW before or in Australia, as far as I know. I am absolutely gobsmacked by the number of people who haven't heard about it

Dan Box: This is a story about a serial killer and his victims are children.

It's raw, immediate and intimate and the audio is visually rich.

And then we meet reporter Dan Box.

DAN BOX: I'm a newspaper reporter.

A couple of years ago I sat down with a cop, who told me about a murder.

Or rather, he told me about three murders.

of three children.

The first was Colleen Walker, a popular, outgoing 16-year-old girl who always

kissed her mum goodbye when she left the house.

The second was Evelyn Greenup, who was quiet, pretty, with a head of tight

curls. She was only four years old.

The third was another 16-year-old, Clinton Speedy-Duroux, a sporty kid who cared about his appearance. He was never seen without his favourite pair of sneakers.

The detective told me all three children had disappeared within five months of each other, all from the same small town in country New South Wales. He told me he was certain who the killer was, but no one had ever gone to gaol.

It's Dan Box's story. He is the "voice" - he's pitch-perfect and slotted right in the true crime genre. He works the microphone closely and intimately. His eye for is for the telling small details: there's the girl with tight curls; the sporty kid and his favourite sneakers; the teen who always kissed her mum goodbye.

It's taken me a long time to visit that town - too long in fact. But when I did, this is what I found - a town divided.

Where the families of the murdered children and the family of the man suspected of their murder live together, on adjoining streets.

Where the first person I talked to told me 'there's a lot of hatred in this town'.

So, I started to ask questions.

Wanted to find out what happened.

How, 25 years after those children were murdered, their killer is still walking around free. 
This is Bowraville, a podcast about innocence and guilt, brought to you by The Australian newspaper.

I'm Dan Box

And there you have it in a nutshell: a story about innocence and guilt, two very clever ideas that drove the story forward in a town where there is a "lot of hatred". The listener has been placed in a very deliberate space.

Indeed in Bowraville, reporter Dan Box inhabits a character so thoroughly embedded in the true crime sleuth trope that you can imagine editors commissioning another series built around his brand.

Phoebe's Fall's opening deployed a similar device: a short montage of voices. (Theme music: Dramatic)

Woman: I remembered answering the phone and said have you found her? And he said, I hope you're sitting down

News archive: the homicide squad has been called in to investigate the death of a woman in Melbourne. The 24-year-old's body was discovered last night on the ground floor of a St Kilda Road apartment building

Man: as soon as I found out how she died, ostensibly by climbing into a garbage chute when she was pissed.

Woman: I don't think she climbed in there by herself

Woman: I have no idea how anybody thinks she could get in that thing

Man: She may have been alive while they were standing there chatting and given a litre or two of intravenous fluids, wouldn't be dead.

Man: no, she didn't get justice by the system because the finding was a complete dud - it was a farce

Woman: it wasn't like this sadness: oh, Phoebe has killed herself. There was far more to it.

It's a detailed and complex opening with problematic production in the grab:

As soon as I found out how she died, ostensibly by climbing into a garbage chute when she was pissed (edit)... ending unnaturally. The speaker is cut off mid-sentence on the wrong inflection. The grab that followed, I don't think she climbed in there by herself... is intended to complete the idea that a crime has been committed. It might work on paper, but not on the ear. The listener is left thinking ' Oh, what was that again?' There is no time for this misstep on audio.

Then we meet the two narrators, Richard Baker and Michael Bachelard.

Michael Bachelard: This is Phoebe's Fall, a podcast from The Age newsroom. I'm Michael Bachelard...

Richard Baker: And I'm Richard Baker.

Michael Bachelard: And we're investigating the short life and brutal death of Phoebe Handsjuk.

The sequence that follows is cued against the sound effect of a typewriter, the journalist writing his copy. 
Richard Baker: (sfx: typing) Melbourne, Thurs 2nd Dec 2010:

At 7pm on this summer evening it was still hot and muggy at a luxury apartment building. A concierge made her way to the refuse room on the ground floor. There had been a fire alarm and she was looking for a broom to sweep up a mess. When she turned the key something blocked the door. She gave the door a shove. It shifted a bit and she peered in. She saw the body of a young woman lying in a pool of blood among the fallen bins. Somehow, 12 floors above, this young woman had squeezed through a narrow hatch one metre off the floor and fallen feet-first 40 metres down the galvanised chute. But it wasn't the fall that had killed her. The blade of a hydraulic contractor virtually severed her foot before the machine spat her out. Blood smeared on the floor shows she crawled around the room looking for an exit until she bled to death from her injuries - alone and in the dark.

Then another stylistic shift as reporter Michael Bachelard breaks the scene.

\section{Michael Bachelard:}

The mystery here is how she got into the chute. The coroner considered the possibilities of murder and suicide. What he ruled was neither. He said Phoebe had climbed in herself in a haze of drugs and alcohol - but that she had not intended to kill herself. According to him this was just a tragic accident. It's an account her family simply does not believe.

I asked Richard Baker why they chose to have two reporters sharing the microphone.

"Why two voices? It was a group decision really for a few reasons. The dynamic allowed us to cover parts of the story where there was no audio or where there was complexity that needed to be simplified by way of a $Q \& A$. And I couldn't question myself!" 6

But instead of simplifying the story, the narration is complicated by two reporters going backwards and forwards against details that are not yet necessary to advance the story of what happened to Phoebe or why I should care about her. This is a classic case of a story getting ahead of itself.

Sometimes it's necessary to ask the difficult questions, like

- can I tell this story for radio?

- or, am I telling the right story?

Three or four minutes in and the story has not begun.

The rush to detail is overwhelming, when what is required is for the story to unfold naturally. We will learn through the series that this is a story about a possible miscarriage of justice. Did Phoebe Handsjuk really die by her own hand, a 'troubling accident' fuelled by drugs and alcohol, as the coroner believed? On the facts, the homicide investigation was thoroughly botched. Basic forensics were not even gathered.

${ }^{6}$ Email to the author, 14 Jan 2017 
And why did the coronial finding exonerate Ant Hampel, when Counsel assisting the coroner said the evidence presented was not conclusive of that deduction? And further, why did the coroner reject Counsel Assisting's recommendation for an 'open finding' on Phoebe Handsjuk's death (which would have left open the possibility the inquest could be re-opened)? As a listener I am left with a deep unease about the conduct of the coronial and the police investigation itself.

Richard Baker clearly thinks there's more to the Hampel story than meets the eye and I "get" all this, but did this drama get buried in the script?

Take this exposition:

MB: In the backdrop there's the spectre of drugs and booze and high society. Phoebe lived with older boyfriend Antony Hampel at the time of her death.

RB: Yeah she did. In fact Ant instructed his lawyers to oppose a coronial inquest. His father is a retired judge and his stepmother is a sitting county court judge.

MB: But an inquest was held and at this point we need to note that the coroner ultimately exonerated Antony Hampel from having any involvement in or knowledge of the circumstances of Phoebe's death, and we are not suggesting otherwise.

RB: But we are re-examining how she died and the controversial aftermath.

MB: Richard, it seems from the very first night she was discovered, that Phoebe and her family were let down by the system?

RB: Yeah that's right, no one checked her for signs of life, no one grabbed the CCTV footage from the building. It was assumed this was suicide very quickly and that's despite there being no fingerprints on the entrance to the garbage chute. There was blood in the apartment, there was also broken glass in the apartment.

Might one narrator writing directly to the unfolding action have been the better device? I'm not yet hooked and the reporters are talking about detail in the story that I can't understand the significance of yet - the coronial inquest, this fellow called Ant, or the significance of his father and stepmother being judges is lost on me.

In another sequence, Bachelard introduces a storyline about one of Phoebe's fantasies, about jumping out of a window:

Michael Bachelard: Almost everyone we spoke to also remarked how much Phoebe loved to climb things. Her friends at art school remembered one time at a party she got drunk and got on top of a building and jumped from roof to roof.

She also told them that her favourite movie scene came from an arthouse film called The Vanishing. In it, a man recounts jumping from a first-floor window onto the cobblestone street below.

Phoebe told her classmates, "I want my life to be like that."

The aim is to create some tension, to suggest that maybe Phoebe did climb into the garbage chute and deliberately plunge to her death. 
So Richard, I felt it was important to include that scene from The Vanishing to illustrate how reckless people say Phoebe was and how physical she was.

Richard Baker: Look, I can see your point but I don't agree. I think it's a real stretch to include this scene. It's way too suggestive that Phoebe put herself in that chute when there's so much doubt. And look, really, who wants to end their life in a garbage chute?

According to Richard Baker, this discussion with Michael Bachelard was included because "we thought this gave the audience a glance behind the scenes to show we are not always on the same wavelength".7

That may be so, but might this story have been told more effectively by building it into the telling of Phoebe's complex, troubled personality and therefore raise doubt and tension about their alternative death narrative, rather than exist as an editorial debating point?

Indeed, too much of Phoebe's Fall was devoted to long (and to my mind sentimental) sequences about Phoebe the woman, and her memorial, which was not germane to the mystery. Absent much of this (but not all), the story might have been more taut and powerful.

\section{The importance of structure}

The makers of Bowraville chose a story built around chronology and this structure therefore required that the story be told against the action of what happened, with each sequence building to the next.

In contrast Phoebe's Fall was told thematically, rather than chronologically. Instead of the listener following the sequence of events that led to her death and the aftermath as if it was in real life (as Alfred Hitchcock observed, drama is life with the boring bits cut out) with backstory thrown in at key moments, we have a story that gets bogged down and fails to move forward naturally. And as a consequence of this, story elements are accorded far greater prominence and length that was needed, while characters like Phoebe's father and grandfather's stories might have been given greater oxygen and longer interviews exploring further what they saw and what they thought.

\section{The need for simplicity and clarity}

I always think about audio as watercolour, text as an oil painting. Put another way, audio is not a place for complex detail

In audio you get one chance for the listener to follow the story, there's no going back to re-reading the script.

\footnotetext{
7 email to the author 14 Jan 2017
} 
And so the inclusion of the sequences on the so-called "tomato soup text" in Phoebe's Fall had me baffled.

This storyline dealt with a mysterious text sent by Phoebe to some family and friends the day before she was found dead. According to family members this text was thoroughly un-Phoebe. We first heard about it Episode 1 and then came back to it in Episode 4.

NATALIE: My first reaction was, she's in trouble JEANETTE: I really didn't know what to make of it because it was, in one way it was totally out of the context of a text she would send to me. It didn't ring true.

As a listener I am intrigued, why is this text (the details of which are unimportant) suspicious? What has this got to do with her death?

The sequence is about whether Phoebe could have sent it (maybe) or did Ant send it (what might this mean?).

Richard Baker: So Michael, if Ant's recollection here about taking the phone for repair on the Wednesday was right then it's hard to see how Phoebe wrote that tomato soup text at 10:30 that morning.

MB: Yeah, it's just another of the mysteries that make Phoebe's story such a mind bender.

Phoebe was still alive when the "tomato soup" text was sent to family and friends; she would be alive for another 36 hours and would speak to several people between when it was sent and when she was found dead.

Richard Baker: OK, before we go any further, let's recap the whereabouts of Phoebe's phone in the last week she was alive. On the Monday and Tuesday, both Ant and Phoebe had the iPhone at various times. On the Wednesday, the day the really weird Tomato soup message was sent, Ant initially said he'd taken the phone to a repair shop as he went in to work.

But if this is true, it's hard to see how Phoebe could have sent that text. But later on, he changed his recollection, and it was more like the Thursday that he took the phone for repair. And of course, that was the day Phoebe died.

But if Ant Hampel did indeed send the text, which is the suggestion, what turns on it? How would this text - an ambiguous, perfectly written text - undermine his alibi? What turns on this text is not something we discover. 


\section{Making the transition to audio from print}

The art of the interview is very different for the journalist not working in the audio medium. For the audio journalist, the interview is partly a performance piece. For the text journalist the interview does not have to fulfil this function, they can make the interview come alive on the page. The audio journalist has to seize the moment.

Dan Box - who has worked in documentaries at the BBC - showed that he grasped that point. The interview was a key dramatic device.

Over at Phoebe's Fall, reporter Richard Baker was putting his toes into the audio space. He alluded to this in one of our email exchanges when he was explaining that an additional reason for having two narrators, was his inexperience, which might also explain why there were fewer interviews that ran on.

"Another reason was my lack of broadcast experience and doubts over whether I could carry off all the narration on my own as well as having my voice in the majority of interviews with key players.

"We got much more competent and confident in our own voices as the series went on, but it was hard at the start. Particularly for me."

"Michael also has a naturally resonant voice which added to the reason to have two voices rather than one".

Getting a script off the page is a daunting experience for most people who have never done it before. Baker's voice is all there. He conveyed great passion and that - along with some breathing exercises, and a good script - is all that is needed. Then he will find his voice. That's what the listener will engage with, not resonance.

What I admire most about Phoebe's Fall - despite my criticisms - is that it's an important story and Fairfax backed its reporters with a new storytelling imperative. It's not surprising that they would feel their way in the medium. .

\section{Interview technique}

In Bowraville, Episode 2, "The Police", Dan Box is telling the story of the forensic investigation and he's just set up Rob Wellings, a police officer who worked on the investigation.

ROB WELLINGS: I located a very small speck of human blood on the vinyl bedhead above the double bed in the caravan and that was analysed in our forensic laboratory unit and identified as human blood.

DAN BOX: Were you able to tell anything more in terms of whose blood?

ROB WELLINGS: Well, this was 1990, it was prior to Australia using DNA techniques, it was hardly even heard of around the world, it was in its infancy in 
Europe and America. In fact the sample was very small. and unfortunately it was destroyed in the analysis by the forensic biologist who identified it was blood.

Dan Box comes back with the payoff question.

DAN BOX: So there's no way of going back since then with improved technology and finding out whose blood it was because that single piece of blood has been destroyed?

ROB WELLINGS: Yeah, that's right.

DAN BOX NARRATION: Which is obviously pretty disappointing. Particularly as Clinton had suffered a blow to the head. Jay was put in trial but found not guilty of killing Clinton. Then years later, a new police strike force was set up to reinvestigate the case. The detective leading it then - and now - is Gary Jubelin. Gary's an interesting character, so I'm just going to let him talk.

The writing out of Wellings into Jubelin is accomplished. Box has written out of the Wellings grab and into the Jubelin with just enough backstory to cue to the essentials.

GARY JUBELIN: We had three children living on the same street murdered over a five month period and the justice system can't bring the person accountable for them to justice, I think the justice system has let them down,. And l'd go further than that, because the justice system is very broad. It's not just the police, it's the courts, it's the media that follow it and it's the community and there was no outrage.

One thing I find unique about this investigation - and I've been doing homicide for a long time, so I get a sense of things that attract the public attention-here you have three kids murdered on the same street and I'm absolutely gobsmacked by the amount of people who have never heard of it or have no understanding of it. Why is that? you speak to the community and they say "That's because we're Aboriginal people and people don't care". I've been working on this for 20 years and, at first, I didn't think they were right, and now I think they were spot on."

Phoebe's Fall relied more on single grabs from talent, rather than letting the character tell their story.

MB: This is another puzzle. Ant and Phoebe were due to have dinner with her father Len that night to celebrate his birthday - strangely, at the same Thai restaurant. So Richard, why is Ant ordering takeaway food?

RB: Who knows? Maybe he thought since Phoebe was missing, that dinner was off? $\quad r$ Maybe he just forgot about it. Maybe he was hungry?

MB: And then something else happened that was a bit odd. The records show Phoebe's dad Len made a call to her iPhone at 6.51pm. Phoebe's grandfather Lorne picks up the story.

LORNE: And uh, Len was running a bit late. And he rang Phoebe's phone... and of course, it went through to message bank. 
MB: But in less than half a minute of that going to Phoebe's phone, Ant Hampel rings him back. Ant Hampel rings him, for the first time in history.

LEN: Well, he'd never before, in the 14-18 months they were together, never called me.

It's a moment with great potential. But why isn't Len telling the story? We don't hear from him about this strange coincidence, or what if anything he said to Ant when they later met at the apartment he shared with Phoebe. And when Ant rang him back, what was their conversation? Instead we have the reporters speculating.

Michael Bachelard: Perhaps Ant was just calling to tell Len he couldn't make it for dinner?

Richard Baker: Well, neither Len nor Ant in their evidence say this. It seems it was just an odd conversation about Phoebe not being there. And Ant didn't even mention the blood near the computer. As for the timing of the call, well, Ant said at the inquest that this was a pure coincidence.

It doesn't seem good enough to be told that the coronial inquest did not hear from them on this matter when the witness, Len Handsjuk, is right there.

\section{The legal hurdles}

One of the great obstacles to Phoebe's Fall was always going to be the lawyers. Bowraville had nothing like this problem, principally because the antagonist could possibly never marshal the legal firepower of the Hampel family, but also because in Bowraville, the main suspect (who cannot be named for legal reasons, as he is now before the NSW Court of Appeal to determine whether he can be retried for murder) was directly asked in interview if he was the killer, which he denied. Combined with reporting that the subject had been acquitted, twice, this probably provided sufficient legal cover for the producers.

But in Phoebe's Fall, there was no opportunity to interview the antagonist, Ant Hampel, no opportunity to outright put to him the questions they had. He flat out refused, and sent off a legal letter warning the producers that Hampel reserved his rights under defamation law.

\section{Biases, crusades and other tricky questions in investigative journalism}

When Dan Box turned up on a panel at last year's OzPod conference at ABC Sydney, he provided a unique insight into the inner workings of the newsroom when he revealed how his editor in chief at The Australian, Paul Whittaker, walked past his desk two days after the first episode and said "we're going to put this bastard in jail". 
Was this bias at work? Some suggested to me that it was because it was seen as evidence of the intent to put a suspect in gaol, and therefore how could the program be seen as fair and balanced.

Here's how Dan Box explained it to Ozpod. ${ }^{8}$

"I don't think anyone got excited (about Bowraville) mainly because they hadn't had a chance to listen to it until after it had gone out. At which point the editor, god bless him, really came on board."

The significance is that the editor realised the power of the story in the first episode, because he'd heard it. This was not journalism that put ideology before the fact of the story gathering. As Dan Box pointed out, Whittaker knew very little about the story as it was in progress.

But once the podcast was released he saw what they had: a sense of injustice was verbalised.

This fervour was then applied to the media strategy around the podcast. Now instead of knocking out a couple of newspaper articles, Box and George were churning out stories including half a dozen for the front page every single day for the three weeks of the podcast run, under the orders of their boss.

Whittaker wanted newspapers to land on the desks of the politicians in Macquarie Street. Yes, it was campaigning journalism (not a dirty word) and we ought not be afraid of it.

Indeed it was partly the force of Bowraville and community pressure that propelled the NSW government in mid-2017 to review the case, and it is now before the Appeal Court. If that appeal is upheld, the main suspect who cannot be named for legal reasons may yet find himself before a judge and jury, charged with all three murders.

Phoebe's Fall left its mark, too. Public pressure has prompted a review of the Victorian Coroner's Act, examining whether they ought to be more ways of revisiting a coronial finding.

Digital technology has democratised the audio storytelling space in a quite profound way. Established radio media, primarily the $A B C$ and $S B S$, no longer have a mortgage on the audio space in Australia. The impact has been a quite extraordinarily creative explosion of courageous audio makers who are telling stories that absolutely need to be told.

While Phoebe's Fall and Bowraville came from former print mastheads - ergo the establishment - new audio entrants are also shaking up the space.

8 OzPod Conference, ABC Sydney, Session 6: 'Hook, line and sinker: how to build an audience.' 4 Oct 2016, at 18 '.36". 
Take Michael Green's phenomenal podcast series The Messenger, about Sudanese refugee Abdul Aziz Muhamat's experience of Australia's immigration detention Centre on Manus Island in Papua New Guinea. The Messenger recently picked up a slew of awards at the prestigious international radio festival in New York, including being named one of 2017's three Grand award winners. It also won a Walkley award in the best radio/audio feature category in 2017.

The Messenger was a collaboration between The Wheeler Centre and the oral history project Behind the Wire, proving that it is not necessary to be 'media' anymore to make great podcasts. The Wheeler Centre is a Melbourne-based literary hub operating out of the State Library with the support of the Victorian Government and patrons Maureen and Tony Wheeler of Lonely Planet publishing, while Behind the Wire is a not-for-profit established with the sole focus of bringing a "new perspective on mandatory detention".

As this space evolves, new voices will emerge. The established players will be challenged in quite profound ways.

There's never been a better time for long form audio investigative journalism.

\section{Editor's Note:}

The editor of RadioDoc Review, Siobhan McHugh, co-produced Phoebe's Fall. She exempted herself from the editing of this article, which was edited by RadioDoc Review Associate Editors Steve Ahern and Mia Lindgren. 


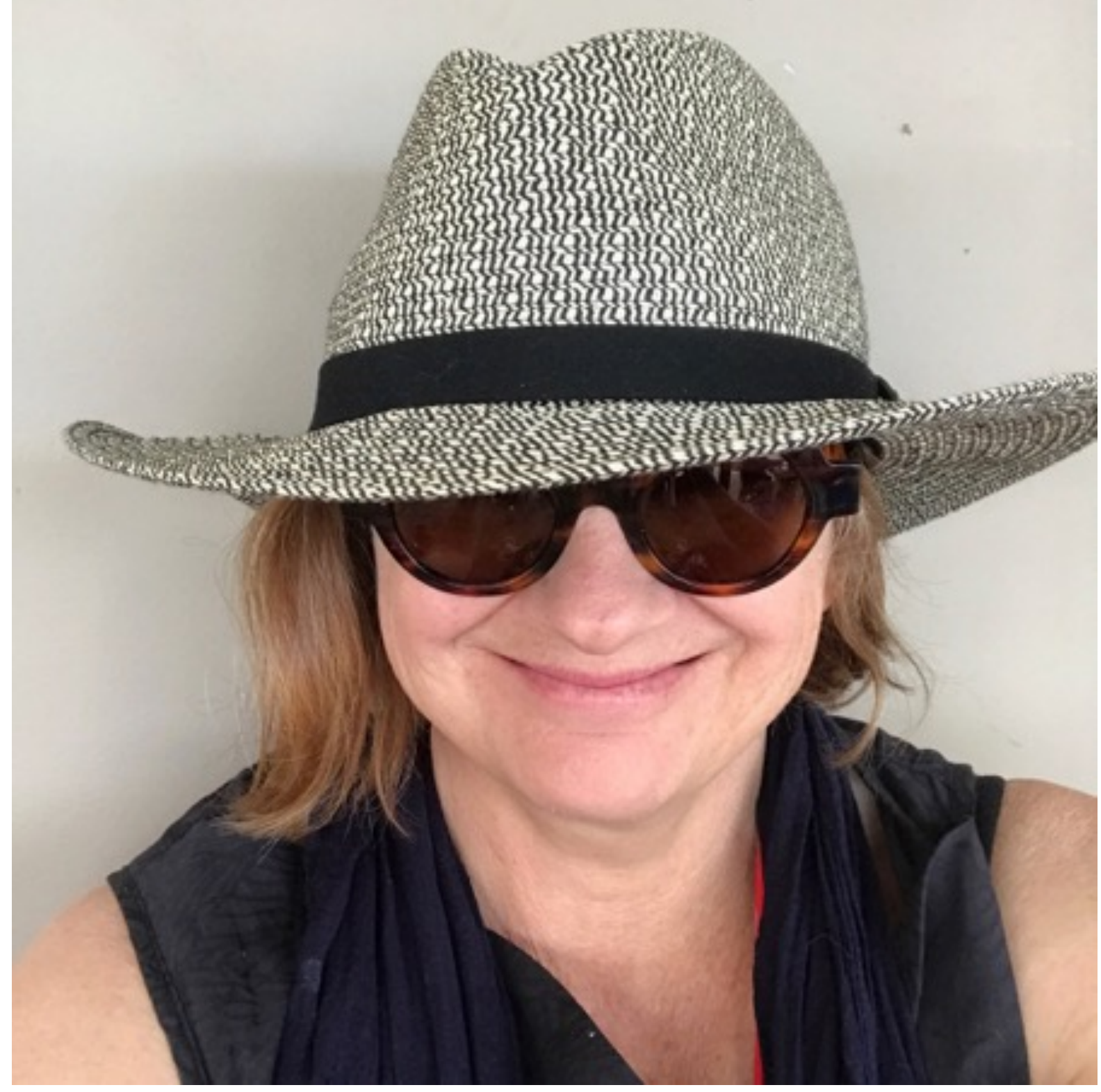

\section{WENDY CARLISLE}

Wendy Carlisle has been a reporter with ABC TV's flagship investigative program Four Corners and was Executive Producer with ABC RN's investigative program Background Briefing until May 2017. She was lead journalist in the ABC's first digital journalism project about coal seam gas and has twice been nominated for a Walkley Award for Excellence in Journalism. 